Surkhet

\title{
Mother Tongue based Multilingual Education (MT- MLE): Teachers' Language Ideologies
}

\author{
- Jnanu Raj Paudel
}

\begin{abstract}
Mother Tongue based Multilingual Education (MT-MLE) is a form of multilingual education built on the learners' mother tongue. This article explores the teachers' ideology on the policy (as policy appropriator). The ideologies of the language teachers have been drawn from the interpretive perspectives where the reality is judged based on the experiences of the research and the researched. The participants in this study covered five English language teachers who have been working in the area of multilingualism. The in-depth interview with them supplied the data for arriving into the results and conclusions. Finally, the teachers unraveled their strong belief on the use of MLE for language promotion and protection of indigenous knowledge.
\end{abstract}

Key words: Multilingualism, Identity, Indigenous knowledge, Linguistic human rights, and Ideology

\section{Introduction}

Language is one of the most contested issues in education, (Liddicoat, 2007) especially in a multilingual country like Nepal where children from different indigenous, tribal, minority groups representing more than 123 languages (CBS, 2011). There has been a long debate in the context of Nepal on whether the language of small communities should be incorporated in the school curriculum in addition to the language of nation. It is hard to understand the legitimized Medium of Instruction (MoI). Many schools have revealed that teaching in mother tongue in the early grades enhances children's ability to learn better than second or foreign language. Some countries opt for one language of instruction, official or majority language, others have chosen to use educational strategies that give national or local language an important place in schooling, (UNESCO, 2003). 


\section{Statement of Problem}

Despite its small size, Nepal is a home of an amazing linguistic diversity. Though there is no reliable estimate of the actual number of language spoken within the country, the Census Report 2011 has recorded 123 national languages in addition to other languages. Rai,( 2005 ) opines that there are three types of languages in terms of their status. These categories are 'moribund languages' which include language such as Kusunda and Koyu, 'endangered languages' which include languages such as Puma and Dhimal and ' killer languages' that include languages like Nepali and English. The languages which are in the categories of moribund and endangered are in the verge of extinction. The 2011 Census Report reported Nepali the largest and the official language, as the mother tongue of $44.6 \%$ of the population, Maithili (11.7\%), Bhojpuri (6.0\%), Tharu (5.8\%). Only 12of 123 languages counted in the Census were spoken by more than one percent of the population (CBS, 2011). There is large number of minority languages having few speakers. Phyak (2007) mentions the use of mother tongue in education assumes great urgency and importance since most of languages are on the verge of extinction owing to the lack of their literate tradition. Though the country is experiencing the democratic reigns, there is no liberal planning but rather adopted Nepali only language policy thereby banning the indigenous languages and other than the standard variety in English (Phyak, 2013). Though the Ministry of Education has implemented the Mother Tongue based Multilingual Education to address the language related issues, the teachers who are the appropriator of the policy have not been unraveled about their language ideology. This study uncovers the teacher perspectives on the policy implemented by the government.

\section{Purpose of the Study}

This study had the following objective:

- To explore English language teachers' ideology on MT- MLE policy.

\section{Research Question}

This study envisaged the answer of following question:

- What are the language ideologies of English language teachers on MT- MLE?

\section{Significance of the Study}

Mother tongue instruction for school education has been an issue of policy debate from the very beginning in Nepal's educational language policies. But the initial policies favored dominant languages as the medium of instruction. Recent policies support MT- MLE at the early grades of basic education and gradual transition to dominant language. It provides conceptual explanation of MT- MLE which helps the stakeholders to understand the related 
thematic issues. The findings of this research will be an important document in the field of education in general and mother tongue to be specific. As the study presents an analysis of the current MLE policy and teachers' ideology, it can be used as a conducive material for the improvement of MT- MLE policy. This study can be a guideline for the stakeholders at planning level especially in the province to draft language policyin education. Additionally, this study is expected to be worthy for all those who are involved in teaching learning activities including the curriculum designers, subject experts, researchers, policy makers, teachers and students. Last, but not least, this work is expected to be highly useful to use as a reference tool, for those who want to carry out further researches in this area.

\section{Journey form Monolingual to Multilingual Policy Education}

Phyak (2011), states that a monolingual policy was adopted by the nation state from the time of unification of modern Nepal. Policy makers at that time were afraid of introducing local languages into schools thinking that it would weaken Nepalese National identity and thwart the development of Nepali language (Weinberg, 2013). During the period of institutional monolingualism, indigenous languages were stigmatized. These languages were neither chosen as the medium of instruction nor were they assigned any educational values to them. The policy was guided by the contemporary politics and sociopolitical milieu of the country (Dhakal, 2015). In the same vein, the monolingual education policy was also supported in the education reports commissioned by Government of Nepal in different times. The Report of Education in Nepal (2011) intends to promote single language (Nepali) mentioning; the medium of instruction should be the national languages in primary, middle and higher educational institutional. Despite this, the advantage of mother tongue instruction is printed claiming that children can easily be made literate if they are taught in their mother tongue. Similarly, All Round National Education Committee (2018) recommends using Nepali as the language of instruction allowing the use of local language. The body of the report favors the single language in education, however, the opinion of the committee members also reveal the importance of using the local languages. Although the report emphasizes the use of English and some foreign languages, it ignores the use of the local languages in education. This language policy resulted that Nepali speaking people excelled over other ethnic and minority languages in education because they could use Nepali ( their mother tongue) in all domains, whereas the indigenous people faced difficulty in expressing their ideas in Nepali since it was not their mother tongue (Phyak, 2013).

The Nepal Education System Plan (2028 BS) accepts Nepali as the language of the nation. The language policy mentioned in the report is assimilatory as it intends to assimilate other languages into Nepali. It indicates that the report has no room for the discussion of the importance of local languages in education. One language and culture was encouraged for promotion during Panchayat regime (Weinberg, 2013). The linguistic awareness that the culture and the language 
are the symbols of ethnic identification increased among the speakers of mother tongue than Nepali following the Peoples' Movement-I. It was reflected when the Constitution of the Kingdom of Nepal (1990) was promulgamated. With the end of Panchayat system in 1990, the issue of language in education came to the forefront. Pressure on the government was put to guarantee linguistic rights through various indigenous people's organizations. As a result, the constitution made the provision for the use of mother tongue in the primary education.

Language Commission Report (1994) in line with the spirit of the constitution gave an impetus to multilingual education. It recommended to adopting bilingual education particularly in schools in the urban and rural areas with bilingual and multilingual context. It also recommended that teaching mother tongue and teaching of other subjects in the language of the nation. The fact that the children should be taught in their mother tongue gradually took pace. Phyak (2011), states that this policy encouraged indigenous children to use their mother tongue in schools and it has also increased their participation in learning activities.

In the Constitution of Nepal 2015 has guaranteed the right for language communities to operate mother tongue schools and the Government of Nepal has agreed to abide most of the most important human right documents of the United Nations. The focus of the use of mother tongue in education has been shifted towards the access and the success of the quality education. Nepal, along with the nations of the world expressed its commitments for education For All (EFA) by the year 2015. To achieve this goal, MT- MLE was employed. The spirit was reflected in the National Curriculum Framework (2005) and School Sector Reform Program (2009). The government of Nepal has also promulgated a critical document for the implementation of mother tongue- based multilingual education program in Nepal.

\section{MT-MLE: Model, Benefits and Challenges}

MT- MLE program as a crucial element of Nepal's English For All (EFA) focusing on the learning needs of non-Nepali speaking children was initiated in 2007. The MLE program included a small scale intervention to build model of MLE in Primary schools. Initially, eight languages seven schools from six districts were selected for piloting. DoE (2009) forms two types of MT- MLE schools: monolingual monograde and monolingual multigrade. Two models of teaching: grade teaching and subject teaching are employed. In the grade teaching model, on teacher teaches all the subjects (except Nepali and English) in the children's mother tongue while, in the subject teaching model, separate teachers teach different subject. Four districts (Dhanusha, Palpa, Kanchanpur, and Rasuwa) have been employing monolingual monograde system whereas two districts (Sunsari and Jhapa) have been employing monolingual multigrade.

There are rationales behind the multilingual education.MT- MLE provides minority language children with sustained instruction through their mother tongue (Taylor, 2010). Research conducted in North America and supports the assertion that there is strong convergent 
evidence between minority language children receiving mother tongue based instruction meet educational success (Heugh, 2009). Phyak (2011) argues that MT- based MLE policy is transformative. It has potential to contribute to social development. It bridges the gap between community and school recognizes the identity, epistemology and voices of local communities. His own observation of MT-MLE class in the school in which MLE programe was piloted show that student experience a better learning environment and feel comfortable expressing their ideas in their own language. It is assumed that the best medium for teaching a child in his/her mother tongue or any other languages the child understands well. The mother tongue is the natural means of self expressions of the experiences and thoughts learnt in childhood. There are other considerations for multilingual education such as academic and educational considerations (Bunyi, 1999). Kandel (2010) writes quoting Jordan that MT- based MLE is very important not only to develop a strong educational foundation but also to strengthen the cognitive development of learners as the beginning of education. MT-based MLE helps strengthen the first language and provides a smooth transition from the first language to the second and the third language. Pointing out the disadvantages of not practicing MT-MLE, Malone (2005) states that the classroom culture, the textbooks and the medium of instruction in schools which are different from the language they know do not serve them to be educated. Instead it may result in: loss of confidence in them as learners; inability to learn official school language well; high repetition, irregularity, and dropout rates; alienation from heritage language and; loss of languages, cultures and knowledge system.

UNESCO (2011) referring to Skutnabb- Kangas (2003) states that if teaching is in a language that indigenous child does not know, the child sits in the classroom the first 2-3 years without understanding much of the teaching. That is why many children leave school without learning either of the languages (mother tongue and the second language) or almost without any knowledge of content. Non-native speaking students have been found to be disadvantaged group in the Nepalese school system, where the medium of instruction is Nepali. The enrollment and participation of non- Nepali speaking students in primary education is low. Their achievement at school is lower than that of Nepali speaking students (Awasthi, 2004).

The opportunity to learn in the mother tongue is also related to linguistic human rights of children. Teaching the mother tongue is valuable teaching learning resources instead of mere source of interference. Furthermore, the medium of teaching also transfers the culture of language used. Even though Nepal has good policies for mother tongue based multilingual education, there are several challenges to its successful implementation. DoE (2009) states that lack of well trained language teachers, less concern of schools and language communities are some major challenges. Phyak (2011) presents the challenges based on his case study in one of the piloted schools. He states that parents' lack of awareness about the importance of the MT- MLE is the major challenge. Parents desire to send their children to private schools assuming that leaning in mother tongue would hold their children learning Nepali and English 


\section{Theoretical and Conceptual Framework}

This study draws upon language ideology (Kroskrity, 2010). Language ideology is beliefs, feelings and conceptions about language structure and use in which often index the political economic interests of individual speakers, ethnic and other interest groups and nation states (Kroskrity, 2010). His idea of three partially overlapping layers of language ideologies has been the basis for the study. First, language ideology represents the perception of language and discourse that is constructed in the interest of a specific social or cultural group. A member's notions of what is true, morally good or aesthetically pleasing about the language and discourse are grounded in social experiences. Standard language ideology is the one under this group which is designed to valorize the standard language and other aspects of mainstream culture while devaluing the non standard and its associated cultural forms. Second, language ideologies are multiple because of the plurality of meaningful social divisions within sociocultural groups that have the potential to produce divergent perspectives expressed as indices of group membership.

The third is related to awareness of local language ideologies articulated by members, researchers and teachers. It recognizes ideologies of practice from the actual usage perspectives. Sociological theorists such as Giddens (1984) who are concerned with human agency and the linkage of micro and macro allow for varying degrees of members' consciousness of their own rule guided activities and ranging from discursive to practical consciousness. This research draws the teachers' ideologies on Mother- Tongue based Multilingual Education based on these theoretical aspects.

\section{Design and Method of the Study}

This is a qualitative study based on the interpretive research paradigm. Interpretivist researchers understand the world of human experience (Cohen, Manion \& Morrision, 2011). Interpretivist researchers discover reality through participants' views, their own backgrounds and experiences (Cresswell, 2003). Interpretivists allow researchers view the world through the perception and experience of the participants. This research method is best suited to the line of inquiry to obtain the desired result since my research is seeking to explore the teachers' ideology on Mother Tongue based Multilingual Education. The reality of this issue is drawn from the interactions among the teachers which interpretivists call socially constructed reality.

\section{Sampling, Tools and Procedure of Data Collection}

Sampling is the act, process, or technique of selecting a representative part of a population for the purpose of determining characteristics of the whole population (Cresswell, 2013).In qualitative research studies, the sample size depends on the scope of the study, the nature of the topic, the quality of the data, the study design, and the use of shadowed data (Morse, 2000, 
2001). Considering all these five things, the participants in this study includesfive English language teachers who have been working in the area of multilingualism. I will select them purposively assuming that they are experienced the phenomenon under study.

I performed in depth interview for the qualitative data, I conductedsemi structured interview based on language ideology theory with the teachers to get rich and thick information on the issue. The interview was conducted in natural setting without being judgmental. I established cordial and collaborative relation and maintained power relation in order to delve in depth data. I conducted the interviews with the teachers according to their convenience. I recorded the information in audio- recording supported by the note keeping.

\section{Analysis and Interpretation of Data}

I employed qualitative data analysis process which includes transcribing, editing, summarizing, organizing, categorizing deriving conclusions of the information collected from various sources. I organized the data collected from participant observation and interview and triangulate them. The patterns, themes, categories and regularities of the data were noted. More importantly, thematic network analysis technique (Attride-Stirling, 2001) has been adopted to generate the global themes from basic and organizing themes. A thematic network was developed starting from the basic themes and working inwards towards a global theme. Once a collection of Basic Themes has been derived; then classified according to the nature of the information and these became the Organizing Themes. Organizing Themes were reinterpreted in light of their Basic Themes and are brought together to illustrate conclusion or super -ordinate theme that becomes Global Theme (ibid).The Global Themes drawn from the Basic and Organizing themes have revealed the teachers' ideology in MT- MLE. I described the themes using the verbatim since key informants are vital people and justice to be done for their exact words (Cohen, Manion \& Morrision, 2011).

\section{Results and Discussions}

Mother Tongue based Multilingual Education (MT- MLE) has been launched by the government of Nepal adopting the top down approach. Educational policy in general and (Ball, 2006) and educational policy in particular (Recento \& Hornberger, 1996) are generally conceptualized and researched as multileveled phenomena and processes utilizing the terms such as macro, meso and micro; top-down and bottom- up; explicit and implicit; overt and covert, de jure and de facto. Similarly, Language policy is often portrayed as multilayered process involving creation, interpretation and appropriation (Johnson \& Johnson, 2014). Language policies are first created then put into motion with open to diverse interpretation and practiced in micro level. The teachers and teacher educators put the policy into practice created by using top down approach where the individuals as the agency to shape the policy are excluded during 
the creation level or macro level. Their agency has not been given space. The mother tongue based multilingual education policy cannot be untouched form this process. The government of Nepal launched the pilot program in MT- MLE in nine minority languages with the goal to develop indigenous/ minority community's capacity to create first language based primary level program in local schools. In this research, I tried to explore the teachers' ideology on the essence of MT-MLE. I conducted indepth interview with language teachers to unravel whether they have informed awareness of the different aspects of language ideology or not; aware of the rationales of this policy including opportunities and challenges. The observations and insights drawn from the teachers' perspective have been organized in the thematic format in the subsequent section.

\section{Ideology, Identity and Capital Dilemma}

Language ideologies are central to language policies. Whether theorized as linguistic culture or as linguistic ideologies, beliefs, about the languages are inseparable from education for at least two reasons (Farr \& Song, 2011): language policy is often carried out through mass education, and education itself is conducted through language.Language ideologies connect the linguistics with the society. Language ideologies are not simply about language but also involve social and cultural convention of personhood (Kroskrity, 2000). Educational language policies are generally conceptualized as multileveled phenomena and process such as processes of creation, interpretation and appropriation. The top- down approach has been adopted by Nepal in which the government has created the policy with possibility of diverse interpretation. Finally it is put in to practice. The teachers are the agency to put it into practice Johnson \& Johnson, 2014).Among the different language ideologies: monolingual, standard and multilingual practiced in Nepal in different times have set out different programs. Most recently, Nepal has implemented Mother Tongue based Multilingual Education with the aim of providing minority language children with sustained instruction through their mother tongue. Teachers, appropriator of language policy have firm multilingual ideology and advocacy for its proper implementation. They are well convinced that the multilingual country like Nepal, multilingual education only can address the diversity of learners in the classroom.

Teachers in the implementation level of educational language policy have commonsense regarding the use of MT- MLE. After Panchayat regime, voices of marginalized communities are recognized leading to the concept multilingual education. The policy addressed the people's desire to have local identity in medium of instruction. The identity conscious ethnic people advocated the approach and have been materialized. The participants in the interview connected identity with language use for instruction. MT- MLE affirms identity. When students feel that their intelligence, imagination, and multilingual talents are affirmed in the school and classroom context, they invest their identity much more actively in the learning process. 


\section{Mother Tongue based Multilingual Education (MT- MLE): Teachers' Language Ideologies}

MT- MLE supporting the diverse linguistic backgrounds of learners claimed the learners in their early learning should be scaffolded by their mother tongue. This policy not only preserves indigenous language and culture but also boosts up indigenous knowledge. It bridges the gap between the learners' home and school language. The learner's mother tongue does not interfere in the acquisition of the second language as advocated by behaviorists rather it works as the resource language similar to the Ruiz's (1984) conceptualization language as resource. It can be linked to Cummin's (1981) interdependence hypothesis suggesting that when children learn a concept in their L1 that knowledge will transfer to another language. The time spent learning an indigenous language is not wasted.

Providing education in the learners' mother tongue assists in promoting ethnic, linguistic and cultural identity. As Siegel (2006) observes children often have the ability to speak standard language but choose to identify with their community rather than the standard language. The standard language policy at school is taken as threatening to ethnic identity. Therefore, resist the education system that promotes it. They share sense of solidarity among the speakers of their own language which leads to the comfortable learning. The ideology and identity principles as common features are contradictory to the learners'capital related concepts.

The teachers I have talked to responded that some speakers of marginalized varieties denigrate their own language and believe in the intrinsic superiority of the standard. Thus they supported the viewof standard language ideologies indicating the better career opportunities. They talked about the stakeholder's dilemma whether to build the children's education foundation in the mother tongue or to adopt more standard language Nepali or to the global language English. The stakeholders (teachers view) sometimes ignore identity issues; advocate for the English medium schools which is more prestigious and supportive for getting better job and career opportunities. The government's Mother Tongue based Mother Tongue Education has created a tension between the identity and economy. The power of English language rules over us with the assumption that English as the medium of instruction is related to cultural capital (Bourdieu, 1990). The society assumes English is the symbol of cultural capital and reveals the power and prestige leading to the dilemma between identity and cultural capital.

\section{MLE to Strengthen Learning}

Mother tongue based Multilingual Education fosters and bolster learning. When children have established a solid basis in the language of schooling through their mother tongue, they can gradually be introduced to learning other languages. Knowledge learned in a language children know can be linked to key vocabulary in another language and the same concept will be understood. A teacher sharing his ideology about the rationale of using mother tongue said: 


\section{Vignette I}

We as a language teacher can use MT- MLE to provide the basic concepts of things, objects, reality, environment, surroundings. It is very easy way to use their mother tongue. The learners won't have to circumlocate the things, hover over the object around the object.

Teacher A advocates the beneficial effect additive multilingualism in which the learner stores the repertoires of two or more language without posing any threat to previous language. This ideology matches Taylor's (2010) view that teachers use children's local knowledge as the basis for their learning; linking and widening it to regional, national and global levels. Teachers can make links between children's indigenous knowledge and concepts in broader society. They can use children's existing schemata and build on them by making analogies, categorization and generalizations. Students' first language represents an important scaffold in certain L2 instructional contexts. Encouraging students to use their L1 when necessary to complete the group task can result in higher quality of L2 output than when students are prohibited from L1 use.

\section{Language Promotion and Linguistic Human Rights}

Providing multilingual education in an additive manner is a kind of respect to culture and society. If all the people just speak standard and global language, other languages will die. When languages die, the culture and the whole anthropological roots die. To keep them alive, it is essential to guaranteelinguistic humanrights implementing mother tongue based multilingual education.Linguistic Human Rights in education are necessary (but not sufficient) prerequisite for both demanding and enjoying most of other human rights (Skutnabb- Knagas, 2000). By including minority languages in the constitution and using them as medium of instruction, they would be protected from dominant languages and their speakers would be less prey of language shift. This study reveals the teachers' multilingual ideology based on mother tongue for language survival, revitalization and promotion. The constitution of Nepal (2015) has guaranteed the Linguistic Human Rights (LHRs) with the right to get education in mother tongue (Clause, $31 \& 32$ ) and right to preserve and promote its languages, script, culture, civilization and heritage. Based on these constitutional provisions, they claim that Mother Tongue based Mother Tongue is to be brought into action to materialize constitutional provision.

Minority language children who are schooled in languages they do not know or have not mastered are in powerless situations unless their communities are in the position to fight and change the status quo (Taylor, 2010). The minority language children are made bold and brought into the position to raise voice to valorize their language in education by acknowledging the linguistic rights in the constitution. 


\section{Conclusion}

Mother Tongue based Multilingual Education has been introduced in education to address the voices of minority communities; valorize language and protects indigenous knowledge. In one hand, implementing three language policy: mother tongue (at primary level), Nepali language (secondary level) and English language (at tertiary level) scaffolds their without subtracting the linguistic repertoires following the additive approach. On the other hand, the policy offers the communities and language groups opportunities to aware about language and its endangerment. The idea behind this notion is to recognize indigenous children's non mainstream Nepali home culture and values; they would be valorized allowing children's self esteem. Similarly, using mother tongue as the medium of instruction protects their language from dominant language which ultimately useful for language identity, language survival, revitalization and promotion, as well as official recognition of oral tradition. The teacher unraveling these language issues emphasized the proper implementation of this policy.

Besides language promotion, they revealed that it supports the whole learning process. Several research studies have shown that children who begin their education in their mother tongue make better start, and continue to perform better than those for whom school starts with a new language. The language of their home acts as resource for the second or the third language in sequence. The teacher have shown the multilingual language ideology which \creating and appreciates cultural awareness, adding academic and educational value, enhancing creativity, bringing adjustment in society and appreciating local languages.

\section{References}

Awasthi, L. D. (2004). Exploring monolingual school practices in multilingual Nepal. Ph. D. thesis. Copenhagen: Danish University of Education.

Ball, S. J. (2006). Education policy and social justice. New York: Routledge.

Bourdieu, P. (1990). The logic of practice. Stanford, CA: Stanford University Press.

Bunyi, G. (1999). Rethinking the place of African indigenous languages in African education. Internatonal Journal of Education Development. Vol. 19. 332-350.

Central Bureau of Statistics (CBS) (2001). Population census report. Kathmandu: Central Bureau of Statistics.

Cohen, L., Manion, L., \& Morrison, K. (2011). The research method in education. London: Rutledge.

Creswell, J. W. (2013). Qualitative inquiry and research design: Choosing among five approaches $\left(3^{\text {rd }}\right.$ ed.). Thousand Oaks, CA: sage.

Cummins, J. (1981). The role of primary language development in promoting educational success for language minority students. In California State Department of Education (ed.), Schooling and language minority students: A theoretical framework. Los Angeles: 
Evaluation, Dissemination and Assessment Center California State University,pp. 3-49. Dhakal, D. N. (2015). Multilingual education in Nepal: Retrospect and prospect. Education and Development, 26 (78- 92). Retrieved from https://www.academia.edu/15570773/ Multilingual_Education_in_Nepal_Prospect_and_Retrospects.

Department of Education (DoE) (2009).Overview of policies and strategies for multilingual education in Nepal.Bhaktapur: Department of Education (MOE).

Farr, M. and Song, J. (2011). Language ideologies and policies: Multilingualism and Education. Language and Linguistics Compass, 5 (9), 650-665.

García, O. (2009). Bilingual education in the 21st century: A global perspective.Malden, MA: Wiley-Blackwell.

Giddens, A. (1984). The constitution of society. University of California Press.

Government of Nepal. (2007). Interim Constitution of Nepal. Kathmandu.Retrieved from http://www.worldstatesmen.org/Nepal_Interim_Constitution2007.pdf

Heugh, K. (2009). Literacy and bi/multilingual education in Africa: Recovering collective memory and expertise. In A. Mohanty, M. Panda, R. Phillipson\& T. Skutnabb-Kangas (Eds.), Multilingual education for social justice:Globalising the local (pp. 95-113). New Delhi: Orient BlackSwan.

Johnson, D. C., \& Johnson, E. J (2014). Power and agency in language policy appropriation. Language Policy. DOI: 10.1007/s10993-014.-9333-z

Kandel, P. (2010). Mother tongue based multilingual education. Nepal: Language Development Center.

Kroskrity, P.V. (2010). Language ideologies- Evolving perspectives. Society and Language Use, 7 (7), PP. 192- 211.

Liddicoat, A. J. (Ed.) (2007). Introduction: Issues in language planning and literacy. Clevedon, UK: Multilingual Matters.

Malone, S. (2005). Education in ethnic minority communities. Questions to consider, problems to solve in UNESCO. Promoting Literacy in Multilingual Situations. Bangkok: UNESCO. Chapter 2.

Ministry of Education (2010). Manual for the implementation multilingual education. Kathmandu:Government of Nepal.

Ministry of Education. (2005). National Curriculum Framework for School Education (PrePrimary to 12) in Nepal. Bhaktapur, Nepal: Curriculum Development Centre.

Ministry of Education. (2009). School Sector Reform Plan 2009-2015. 2009. Kathmandu: Ministry of Education.

Morse, J.M. (2001). Determining sample size. Qualitative Health Research. Vol.10, PP.3-5.

Nepal Education Planning Commission (NEPC) (1956). Education in Nepal: Report of the Nepal

Phyak, P. (2007). Mother tongue education practices and problems with reference to Limbu language. A research report submitted to (SIRF/A07) SNV. Nepal. 
Phyak, P. (2011). Multilingual education, social transformation and development in Nepal. Retrieved from http://www.langdevconferences.org/publications/2011-Colombo Sri Lanka/10-LanguageandSocialCohesion-Chapter10.pdf

Phyak, P. (2013). Language ideologies and local languages as the medium of instruction policy: A critical ethnography of a multilingual school in Nepal. Current Issues in Language Planning 14 (1), 127-143.doi:10.1080/14664208.2013.775557

Rai, V.S. (2005).Endangered language, moribund language and killer language. InYadav, Y.P. (eds.) Contemporary issues in Nepalese Linguistics. Kathmandu:

Recento, T. K. and Hoenberger, N. H. (1996). Unpeeling the onion: Language planning and policy and the ELT professional. TESOL Quarterly, 30 (3), 401-427.

Siegel, J. (2006). Language Ideologies and the education of speakers of marginalized language varieties: Adopting a critical awareness approach. Linguistics and Education, 17, 157174.

Skutnabb- Kangas, T. (2000). Linguistic genocide in education- or worldwide diversity and human rights? Mahwah, NJ: Lawrence Erlbaum.

Strier, D. R., \& Sands, G. R. (2014). Moving beyond the official story when others meet in qualitative interview. Qualitative Research, 15 (2), 251-268. doi: $10.1177 / 1468794114548944$

Taylor, S. K. (2010). Beyond bilingual education: Multilingual language education in Nepal. Education and Learning Research Journal, 138-154.

UNESCO (2011). Multilingualism and education in Nepal: Hearsay and reality. Kathmandu: UNESCO Kathmandu Office.

UNESCO. (2003). Language vitality and endangerment. Document submitted to the International expert meeting on UNESCO program safeguarding of endangered languages: Paris.

Weinberg, M. (2013). Revisiting history in language policy: The case of Instruction in Nepal. Working Papers in Educational Linguistics Vol. 28 (1), PP. 61-80 